\title{
A CONCEPT: FACTORS INFLUENCING SHARING TACIT KNOWLEDGE IN PUBLIC SECTOR ORGANIZATION
}

\author{
Kurniawati Desi Tri \\ Faculty of Economics and Business, University of Brawijaya, Indonesia \\ E-mail: desirayhan@gmail.com
}

\begin{abstract}
Sharing tacit knowledge is a personal and more practical knowledge sharing based on someone's experience and skill. This research aimed to determine the process of sharing tacit knowledge in a public sector organization by putting several variables of organizational culture and servant leadership as antecedent and trust as mediation. This research was a combination of the previous model; it did not appear a new basis theory since it was an interaction of the previous research but more focusing on government organization. This research was practically expected to provide information to government organization on the factors influencing sharing tacit knowledge.
\end{abstract}

\section{KEY WORDS}

Organizational culture, servant leadership, trust, sharing tacit knowledge.

Public sector workers are encouraged to be a knowledgeable staff so that able to provide satisfying service to society. That can be achieved by a worker with a featured knowledge (Muluk, 2008). Staff and tacit knowledge owned are one of the important resources in an organization. However, tacit knowledge management is relatively more difficult (Ambrosini and Billsberry, 2007), since tacit knowledge is abstract, attached to an individual, and the existence is not fully realized (Faust, 2007; Stenmark, 2000).

According to Collins (2001), knowledge in an organization is dynamic and depends on the social relationship among the individual to create, share, and make use the knowledge. A large number of tacit knowledge is divided informally and this process depends on the working environment culture. Another problem frequently appearing in the fields of tacit knowledge is how the staff can share the knowledge with the supervisor (Nonaka et al., 2009). Moreover, in order to get an experience which will provide tacit knowledge, it needs a trust-each-other-relationship and close interaction. In terms of new context, this experience must have right involvement with tacit knowledge holder (Levin \& cross, 2004; Holste \& Fields, 2010). Previous research result indicates that the utilization of tacit knowledge in an organization is not maximal yet (Probst et al., 2000; Stemark, 2000). Additionally, Dirks \& Ferrin (2002) in a leadership theory have found that trust will influence organizational leadership setting; the use of leadership concept can be a key to optimize the success of encouraging the behavior of sharing tacit knowledge in working area.

Problem Gap. A previous study conducted by Foos et al., (2006) found that characteristic similarity of social, personal, and culture, understanding as well as vision and goal similarity in a company between the side of source and receiver is a factor supporting the process of sharing tacit knowledge. Borges' research (2013) found that personality and consciousness are the most influential characters in relation to the behavior of sharing tacit knowledge. According to Supiah and Sandhu (2011), organizational culture type influences the behavior of sharing tacit knowledge both good and bad influence. According to that review, it can be found that there is an opportunity of research development on the sharing tacit knowledge which was previously conducted by a company (Foos et al., 2006), influenced by personality and consciousness (Borgess, 2013), and the type of organizational culture (Supiah and Sandhu, 2011). As the research development, sharing tacit knowledge of this research will be applied to public organization especially in the government office. The researchers want to know the impact of sharing tacit knowledge under the difference of organizational culture condition and leadership in public sector organization. 
Furthermore, Rezaei et al., (2012) proposed that the relationship between servant leadership with the trust as the basis of servant leadership effectivity towards sharing tacit knowledge. It was also supported by Goh and Jie's (2014) research stating that a good relationship between servant leadership and the shared trust to become an affective-based trust and cognitive-based trust influence the effort of improving commitment in an organization. Dehaven (2007) stated that manager's perception of knowledge management and the influence of servant leadership influence the adjustment and the use of knowledge management. According to those findings, it can be predicted that knowledge transfer is also influenced by leadership style of an organization.

According to the research of Alony et al., (2007), trust is a factor supporting the process of sharing tacit knowledge under the existence of trust-each-other-feeling so that bringing a training relationship which is also the supporting factor of sharing tacit knowledge process. Clinton's (2011) finding shows that trust builds an indirect impact on the effectiveness and accessibility of sharing tacit knowledge. Trust is based on someone's expectation of others and this creates awareness. Unique ability development leading to the tacit knowledge depends on the existence of effective trust among the individual. Renzl (2008) stated that trust in management specifically increases the behavior of sharing tacit knowledge through the decrease of being afraid of losing someone's unique value and increase a willingness to document knowledge. Thus, it can be said that trust in an organization influences sharing tacit knowledge among the individual in an organization.

Problem Statements. This conceptual research aims to identify what factors that greatly affect sharing tacit knowledge in a government organization. According to that background and previous research gap so that the problem statements were as follow:

- Do organizational cultures, servant leadership style, trust in public sector organization influence sharing tacit knowledge?

- Do organizational culture and servant leadership influence trust among employees in an organization?

- Does trust mediate the positive influence of organizational culture and servant leadership on sharing tacit knowledge?

\section{LITERATURE REVIEW}

Knowledge Management. Knowledge identification is in light of the analysis and any knowledge description in internal and external organizational environment. Knowledge acquisition is a process to get knowledge from an external organization. Knowledge development includes all business aimed to develop capability which organization has no yet. The type of knowledge development process is among other new skill development, new product, better ideas, and more efficient processes. Knowledge distribution is a process of the existing knowledge transfer and distribution in an organization.

Knowledge utilization process is a beneficiation process of all knowledge owned by the organization in a productive way for organizational benefits. Knowledge retention process includes selection, storage, and knowledge updated periodically. Knowledge retention is an important process to prevent the loss of knowledge from the organization. This knowledge retention depends on the use of all storage media owned by organization efficiently. Knowledge target defines organization major knowledge and determines the type and level of skill which will be needed by an organization. Knowledge assessment process plays a role to assess the improvement of a learning process. Knowledge target will be a reference in a process of knowledge assessment (Probs et al., 2000).

Tacit knowledge. Tacit knowledge was a type of knowledge which was difficult to be expressed, explained and transferred, and practice in nature as well as being in the specific context (Nonaka, 1991; Polanyi, 19660. Moreover, Nonaka (1991) explained that tacit knowledge was personal in nature and difficult to be stated in a real form, thus it was very hard to be communicated with others. Nonaka (1991) also stated that there were two dimensions in tacit dimension, that was technical dimension including proficiency, and 
cognitive dimension "the know-what" consisting believe, idea, and value which was commonly considered insignificant.

One of the interesting characteristics of tacit knowledge was the gap between its value on the one hand and the elusive nature on the other. The high value arising from the facts being the source of this knowledge comes from can be known but difficult to declare. An elusive nature of tacit knowledge can be derived into at least two reasons; (1) someone does not fully aware of tacit knowledge owned, and 2) the lack of someone's intensity in the efforts of bringing the knowledge becomes explicit.

Sharing Tacit Knowledge. Tacit knowledge is an important element in industry collaboration both as a factor initiating collaboration and succeeding that collaboration. Tacit knowledge is a key factor of competitive superiority in collaboration. Tacit knowledge transfer only can be done through personal interaction and observation. A method can be used to sharing tacit knowledge is a mentoring program. At the mentoring program, the receiver can interact personally with source party and make an observation to the application of tacit knowledge conducted by the source party at the same time (Faust, 2007).

Sharing tacit knowledge is a knowledge transfer owned by an experienced individual in a particular field but is difficult to be expressed and more practice in nature (Nonaka, 1991: Polamyi, 1996). Sharing tacit knowledge truly depends on the special level of someone's social relations. Nonaka (2000) emphasized that tacit knowledge can be transferred into formal language, electronic storage towards tacit knowledge will be difficult to get a place, and for that reason, it enables something to lose the knowledge. Alwis et al., (2004) stated that tacit components of innovation only can be developed through practical experience, or personal interaction with an expert having experience or relevant knowledge, both internal and external organization and social network.

Measurement of Sharing Tacit Knowledge. Measurement of sharing transfer knowledge can be done by a similar approach to the measurement of knowledge transfer, but there is a little difference. Not all tacit knowledge can be captured by a verbal report, which is commonly used to measure knowledge. Performance-based measurement approach is more appropriate to measure tacit knowledge than approach measuring knowledge directly (Argorate and Ingram, 2000). There are five knowledge storages of the organization i.e. (a) individual member, (b) organizational chart and function, (c) standard operating procedure and organizational practices, (d) organizational culture, and (e) physical structure of working place (Argote and Ingram, 2000).

\section{METHODS OF RESEARCH}

This was an explanatory research. Explanatory research can explain the relationship between the variable in a causal relationship (Saunders et al., 2009). This research was conducted at government office under the expectation of being able to increase the performance of integrated service unit that directly relates to the community or shareholder. Later on, relationship prediction among the variable was conducted based on the analysis of similar previous research. The current conceptual paper was aimed to explain the relationship in a detailed way among the variable in a cognitive way.

\section{RESULTS AND DISCUSSION}

Organizational culture was a collection of result from the various cultures in society brought by previous staff which was agreed on as behavior guidance that has to be agreed (Pettigrew, 1979). As a result, community culture and organizational culture will create an attitude value, individual, assumption behavior and expectation reflected in an organizational behavior in which the workers perform their duty. Stoddart's (2007) research significantly found the impact of collaborative culture and group-oriented in a behavior of sharing knowledge. The sense in a community helps the organization to achieve a morecollaborative-culture and team-oriented, which in its turn help to encourage sharing knowledge. 
For that matter, collaborative and team-oriented organizational culture was expected to influence employee involvement in the behavior of sharing knowledge. Stoddart's (2007) research found that the impact of collaborative and team-oriented culture has an influence on the behavior of sharing knowledge. Supiah and Sandhu (2011) found that organizational culture has an influence on the behavior of sharing tacit knowledge both good and bad influence. Considering the previous research result in relation to the organizational culture and the behavior of sharing knowledge, then it can be concluded a proportion like this below:

Organizational culture has a positive influence on sharing tacit knowledge.

Servant leadership was a leadership style realized by specific practices from servantleaders (Keith, 2008). There were seven specific practices of servant leadership: personal awareness, listening, changing pyramid, building colleague, training not controlling, mobilizing energy and another smart potential, having a foresight (Keith, 2008). Song et al., (2015) stated that collaboration between servant leadership and knowledge will increase organizational achievement which in this field is company's selling achievement. In addition, Dehaven (2007) stated that managers who practice servant leadership style were a reflection of their value to share knowledge, build a relationship and develop others' ability. Therefore, according to those several findings, it can be proposed a proposition like this below:

Servant leadership has a positive influence on sharing tacit knowledge

According to Mayer et al., (1995), trust is a desire of the parties towards others' behavior based on the expectation that other parties can do a particular action to the trustee. According to Mayer (1993), there were three factors of someone's trust former to other that was ability, benevolence, and integrity. Mayer and Gavin (2005) led to trust in management to analyze the impact on achievement and the ability to commit staff's attention to the duty that has to be finished in order to add their company's value.

Trust was found influencing the quality development of exchange relationship of employer-employee (Deluga, 1994; Brower et.al, 2000) and various knowledges (Yen and Chang, 2007). Trusts open an opportunity to get an access to the valuable knowledge and political resources, economy, and relational. At the end of the time, a stable and strong relationship from human, social and cultural capital was realized as a not limited competitive advantage (Savolainen, 2011). According to that explanation, the proposition concluded was as follow:

Trust has a positive influence on sharing tacit knowledge.

According to Appelbaum et al., (2004), organizational culture also has a direct relationship with trust; this research result stated that there was a significant relationship between organizational culture and trusts. In addition, leadership style in an organization also has a relationship on organizational culture and trusts. A study conducted by Wiewiora et al., (2014) stated that it was found a clue of relationship pattern between organizational culture, trusts and sharing knowledge mechanism. This research result releases that organizational culture influences view on trusts value during the process of sharing knowledge among the workers. According to that explanation so that the proposition is as follow:

Organizational culture has a positive influence on trusts.

Razaei et al., (2011) investigated that servant leadership and organizational trusts have a positive influence on leader trust and organizational communication as the mediator. On the other hand, Goh and Jie (2014) through their research suggested that organizational leader needs to train their servant leadership if want to improve their staff's trust so that the staff become more participates and support organizational activity. Trusts divided into effective and cognitive become a mediator of the relationship between servant leadership and organizational commitment. Up-to-down conventional leadership and hierarchy pyramid should not be a focus on the manager if want to get a staff with high trusts and commitment. As a result, it is proposed to be a proposition like this below:

Servant leadership has a positive influence on trust.

Someone's social relationship level influences one's level of trust to others. According to Burke et al., (2007), trust is a process resulted from a collaborative interaction between organizational player in a process of communication, cooperation and sharing information. Borges (2013) stated that organizational culture, personality, and social relationship have a 
positive influence. In which social environment can improve closeness among the individual in one organization. Those findings influence proposition arrangement like this below:

Trust mediates the influence of organizational culture on sharing tacit knowledge.

While Schaubroeck et al., (2011) found the relationship result of leadership style to the team performance will be stronger when there were a communication and trust within. According to those findings, the proposition was as below:

Trust mediates the influence of servant leadership on sharing tacit knowledge.

This research result can give a contribution in theory application deepening developed in a research related to the sharing tacit knowledge in the previous researchers. This research was a development of the existing model by combining 4 research variables i.e. organizational culture, servant leadership, trust, and sharing tacit knowledge. Considering previous research, sharing tacit knowledge was influenced by two organizational factors (Supiah and Sandu, 20122; Borges, 2013), leadership style (Singh et al., 2008; Song et al., 2015) and trust (Renzl, 2008; Hostle \& Field, 2010). However, there was no previous study combining those four variables in one concept.

This study is still limited to conceptual and theoretical analysis. However, a conceptual analysis will have a maximum result in the future empirical study. Therefore, this study limitation is expected able to conduct an empirical study on the next research.

\section{CONCLUSION}

According to the analysis of previous research, it can be concluded that in a government organization, it needs sharing tacit knowledge to increase service quality to the community. In addition is found an indication of a positive relationship between organizational culture, servant leadership and trust to the behavior of sharing tacit knowledge among the workers. More is found that trust as mediation is able to improve the relationship between the organizational culture and servant leadership to the behavior of sharing tacit knowledge.

\section{REFERENCES}

1. Alony, A., G. Whymark \& M. Jones. (Ed. Cohen, E). 2007. Sharing Knowledge tacit: A Case Study in the Australian Film Industry. Informing Science Journal. Vol. 10.

2. Ambrosini, V. \& J. Billsberry. 2007. Person-Organisation Fit as an Amplifier of Pengetahuan tacit. Virtual Pro.

3. Appelbaum, S., N. Bartolomucci, E. Beaumier, J. Boulanger, R.Corrigan, I. Core, C. Girar, \& C.Serroni. 2004. Organizational Citizenship Behavior: a case study of culture, leadership, and trust. Management Decision. Vol. 42. No. 1. p. 13-40

4. Argote, L. \& P. Ingram. 2000. Knowledge Transfer : A Basis for Competitive Advantage in Firms. Organizational Behavior and Human Decision Processes. Vol. 82. No. 1. Academic Press

5. Borges, R. 2013. Tacit knowledge sharing between IT workers, The Role Of Organizational culture, personality, and social environment. Emerald Management Research Review. Vol.36. No.1.

6. Brower, H.H., F.D. Schoorman, \& H.H Tan. 2000. A Model of Relational Leadership: the integration of trust and leader-member exchange. The Leadership Quarterly. Vol. 11. No. 2. p. 227-250.

7. Burke, C.S., D.E. Sims, E.H. Lazzara \& E. Salas. 2007. Trust in leadership: a multi-level review and integration. The Leadership Quarterly. Vol. 18. p. 606-632.

8. Clinton, Bridgett. 2011. Organization knowledge sharing tacit through organizational culture and trust. University of Maryland, USA: Published Dissertasion.

9. Collins, H. M. 2001. Tacit knowledge, trust and the $Q$ of sapphire. Social studies of science. Vol. 31. No.1. 
DeHaven, David B. 2007. The influence of servant leadership on manajemen pengetahuan: an investigation of certifeid pengetahuan manager perceptions, Capella University, USA: Published Dissertasion.

Deluga, R.J. 1994. Supervisor Trust Building, Leader-member Exchange and Organizational Cintizenship Behavior. Journal of Occupational and Organizational Psychology. Vol. 67. No. 4. p. $315-326$

Dirks, Ferrin. 2002. Trust in Leadership: Meta-analytic findings and implications for research on practice. Journal of applied psychology.

Faust, B. 2007. Implementation of Tacit Knowledge Preservation and Transfer Methods, International Conference on Knowledge Management in Nuclear Facilities. Vienna, Austria.

Foos, T., G. Schum, \& S. Rothenberg. 2006. Tacit Knowledge Transfer and the Knowledge Disconnect, Journal of Knowledge Management. Vol. 10 No. 1, Emerald Group Publishing.

Goh, See-Kwong \& Brian Zhen-Jie. 2014. The Influence of Servant leadership towards Organizational Commitment: the mediating role of trust in leaders. International Journal of Business and Management. Vol. 9. No. 1. p. 17-25.

Holste, Scott \& Dail Fields. 2010. Trust and tacit knowledge sharing and use, Journal of Knowledge Management. Vol. 14. No.1. p. 128-140.

Keith, Kent M. (2008) The Case for Servant leadership. The Greenleaf Center for Servant leadership. Westfield, Indiana.

Levin, D. Z. \& R. Cross. 2004. The Strength Of Weak Ties You Can Trust: The Mediating Role of Trust in Effective Knowledge Transfer. Management science.

Mayer, R.C. \& Mark B. Gavin. 2005. Trust in Management and Performance: Who minds the shop while the employees watch the boss?. Academy of Management Journal. Vol. 48. No. 5. p. 874-888

Mayer, R.C., J.H. Davis, \& F.D. Schoorman. 1995. An Integrative Model of Organizational Trust. Academy of Management Review. Vol. 20. No. 3. p. 709-734.

Muluk, K.M.R. (2008) Manajemen pengetahuan: Kunci Sukses Inovasi Pemerintahan Daerah. Bayu Media FIA UNIBRAW, Malang.

Nonaka, I. 1991. The Knowledge Creating Company. Harvard Business Review. Vol. 69. No.3, p. 27-38.

Nonaka, I. \& Von Krogh, G. (2009), Tacit Knowledge and knowledge conversion: controversy and advancement in organizational knowledge creation theory, Organization Science. Vol. 20. No. 3. pp. 635-652.

Pettigrew, A.M. 1979. On Studying Organizational Cultures, Administrative Science

Polanyi, M. 1966. The Tacit Dimension. Routledge \& Kegan Paul Ltd. London.

Probst, G., S. Raub, \& K. Romhardt. 2000. Managing Knowledge Building Blocks for Success. John Wiley \& Sons Ltd. Chichester, England.

Renzl, B. 2008. Trust in Management and Knowledge Sharing: The Mediating Effects of Fear and Knowledge Documentation. The International Journal of Management Science. Vol. 35. p. 206-219.

Rezaei, M., S. Salehi, M. Shafiei, \& S. Sabet. 2012. Servant leadership and Organizational Trust: the mediating effect of the leader trust and organizational communication. Emerging Markets Journal. Vol. 2.

Saunders, M., Philip Lewis, \& Adrian Thornhill. 2009. Research Methods for Business Students. Fifth Edition. p. 362.

Savolainen, Taina. 2011. Leadership by trust in renewing human intellectual capital in Puusa, A. dan Reijnen, H., (Ed.) Aineeton Paaoma Organizaation Voimavarana. Finland

Schaubroeck, J., Lam, S. S., \& Peng, A. C. (2011). Cognition-based and affect-based trust as mediators of leader behavior influences on team performance. Journal of Applied Psychology. Vol. 96. No.4.p. 863- 871

Singh, Sanjay Kumar. 2008. Role of leadership in Knowledge Management: A study. Journal of Knowledge Management. Vol. 12. No. 4. p. 2-15.

Song, Chanhoo. 2015. Servant leadership and team performance: the mediating role of knowledge-sharing climate. Social Behavior and Personality. Vol. 43. No. 10. p. 1749-1760. 
Song, Chanhoo. 2015. Servant leadership and team performance: the mediating role of knowledge-sharing climate. Social Behavior and Personality. Vol. 43. No. 10. p. 1749-1760.

Stenmark, D. 2000. Turnin Tacit Knowledge Tangible, Propositions of the 33rd Hawaii International Conference on System Science. Hawaii, U.S

Stenmark, D. 2000. Turnin Tacit Knowledge Tangible, Propositions of the 33rd Hawaii International Conference on System Science. Hawaii, U.S

Stoddart, L. 2007. Organizational culture and knowledge sharing at the United Nations: using an intranet to create a sense of community. Knowledge and Process Management. Vol. 14. No. 3.

Suppiah, V. \& M.S. Sandhu. 2011. Organisational culture's influence on tacit knowledgesharing behavior. Journal of Knowledge Management. Vol. 15 No. 3.

Wiewiora, A. et al. 2014., Interactions Between Organizational Culture, Trustworthiness, and Mechanisms for Inter-Project Knowledge Sharing. Project Management Journal. Vol. 45. p.48-65. 